\title{
EDITORIALS
}

\section{Anticipating the outcomes and care choices for people living with COPD}

See linked articles by Cleland et al. on pg 255 and

Seamark et al. on pg 261

\section{*Dianne Goemana, Julia Walters ${ }^{\mathrm{b}}$, Carolyn Ross}

a Senior Research Fellow, Royal District Nursing Service, Helen Macpherson Smith Institute of Community Health, St Kilda, Victoria, Australia

b NH \& MRC Primary Care Research Fellow, Menzies Research Institute, Tasmania

Associate Professor and Assistant Dean, Faculty of Nursing, University of Alberta, Alberta, Canada

*Correspondence: Dr Dianne Goeman, Royal District Nursing Service, Helen Macpherson Smith Institute of Community Health, 31 Alma Road, St Kilda, Victoria 3182, Australia

Tel: (03) 95365318 Fax: (03) 95365300

E-mail: dgoeman@rdns.com.au

In this issue of the $P C R J$ are reports of two qualitative studies from the UK investigating aspects of organisation of care for COPD. Cleland et al. ${ }^{1}$ in Aberdeen, Scotland investigated stakeholder views of a community-based anticipatory care service (CBACS) for COPD, and Seamark et al. ${ }^{2}$ in East Devon investigated the opportunity for advance care planning (ACP) in COPD. While ACP for people with advanced COPD is widely understood both in the $\mathrm{UK}^{3}$ and in other developed countries as addressing patients' holistic needs including psychological, social and financial needs, an anticipatory care service in COPD is less well defined. Cleland et al. describe the role of a CBACS' as not only responding to symptoms but also addressing health promotion to prevent exacerbations. The aim of such a service is therefore to deliver better outcomes for people living with COPD and to reduce hospital admissions, emergency department attendance, and urgent general practitioner (GP) visits. Seamark et al. ${ }^{2}$ address the narrower (often neglected) aspect of ACP, which requires patient understanding about prognosis and options for end-of-life care.

Qualitative research methods are ideally suited for exploring people's perceptions and attitudes using strategies such as focus groups and/or in-depth interviews ${ }^{4}$ - as was the case in these two studies. In the Seamark study, the qualitative approach is used to understand patient views about when and who should introduce the topic of advance care planning, ${ }^{2}$ and in the Cleland study it is used to examine the attitudes of a range of stakeholders - patients, carers and healthcare providers currently delivering COPD care - to a potential new service. ${ }^{1}$ The results of qualitative research, although limited in generalisability, can be a powerful tool for sensitising policymakers and practitioners to the perceptions of health service users and healthcare professionals. In turn, this disclosure can be the impetus for changes in healthcare delivery and health professional education which are needed to provide more cost effective care for chronic diseases such as COPD. ${ }^{5}$

Although a CBACS for COPD with the potential to reduce hospitalisation was broadly acceptable to stakeholders, key benefits identified were patient education, patient-centred care and patient empowerment. ${ }^{1}$ This fits with a shift in focus by policy makers in the community healthcare sector to implement models of care that are 'person-centred', 'goal-oriented' and enabling. ${ }^{6}$ A 'person-centred' approach to care encourages working with clients and/or their carers to achieve greater independence and wellbeing and the maintenance of independence for as long as possible, provided management can be done in a safe and effective way. ${ }^{7}$

Cleland et al. ${ }^{1}$ did not directly address the fact that these objectives are also those of existing health care providers who care for COPD patients in general practice ${ }^{8}$ and in outreach services for COPD such as assisted-discharge service and hospital in the home. ${ }^{3}$ The findings did suggest that a CBACS could engage directly with existing services, but necessary linkages were not clearly defined. There was no consensus on the professional groups that would contribute to any new service, and resources for such a new service were recognised as limited. Stakeholders working in primary care and community nursing made it clear that they had no capacity to assume additional clinical, managerial or organisational responsibilities, although there were concerns for GPs if other healthcare professionals assumed leadership in a CBACS. Increasingly it is recognised that improved competencies for inter-professional collaboration can increase the consistency, continuity, and cost effectiveness of care. In Canada, the UK, New Zealand and the USA, policy makers are calling for changes in health professional education to improve collaborative practice. ${ }^{9}$

Findings from the study by Seamark et al. ${ }^{2}$ confirm both the need for, and the well-documented difficulty implementing, ACP for patients with COPD. No patients could recall discussion in hospital about issues of resuscitation, the possibility of being ventilated, or planning for future exacerbations. The lack of follow-up instructions at the point of hospital discharge is a critical gap in transition of care recently reported in an 11-country survey. ${ }^{5}$ The logistic barriers to ACP inherent in the chaotic nature of hospital admission are understandable and probably not amenable to change. Patients' preference for their GP as someone they knew and with whom they could engage in ACP discussions in a non-hospital setting is supported by other studies. ${ }^{10}$ However, this may be problematic, since GPs are already seen as being poorly placed with respect to both time and resources in order to deliver asthma or COPD education. ${ }^{11}$ 
These two qualitative papers contribute to the development of new and innovative models of providing aspects of COPD care and shared decision-making. Their findings suggest that there is a need for ongoing debate regarding workforce issues and the development of appropriate competencies even in the highly centralised UK National Health Service. However, there are also other models - for example, the use of a hospital-based dedicated healthcare professional to promote discussion of ACP with patients directly ('Respecting Patient Choices $^{\prime 12}$ ) currently in use in Australia and the USA. The role of other models should also be investigated.

Nevertheless, given the growing burden of disease from COPD resulting from changing demographics, ${ }^{13}$ it is clear from both papers ${ }^{1,2}$ that patient choices will be necessary, and that changes to traditional health service delivery (including the roles of health service providers) will be required, in order to accommodate the projected increase in demand.

Conflicts of interest DG is an Associate Editor of the $P C R J$, but was not involved in the editorial review of, nor the decision to publish, this article. JW and $\mathrm{CR}$ declare that they have no conflicts of interest in relation to this article.

Commissioned article; not externally peer-reviewed; accepted 16th July 2012; online 26 July 2012

(C) 2012 Primary Care Respiratory Society UK. All rights reserved

http://dx.doi.org/10.4104/pcrj.2012.00067

Prim Care Respir J 2012; 21(3): 241-242

\section{References}

1. Cleland J, Moffat M, Small I. A qualitative study of stakeholder views of a communitybased anticipatory care service for patients with COPD. Prim Care Respir J 2012;21: 255-60. http://dx.doi.org/10.4104/pcrj.2012.00008
2. Seamark D, Blake S, Seamark $C$, et al. Is hospitalisation for COPD an opportunity for advance care planning? A qualitative study. Prim Care Respir J 2012;21:261-6. http://dx.doi.org/10.4104/pcrj.2012.00032

3. NICE UK. Services for people with chronic obstructive pulmonary disease; Accessed 29/06/12: Available from: http://publications.nice.org.uk/services-for-people-withchronic-obstructive-pulmonary-disease-cmg43/43-specifying-supportive-andpalliative-care-for-people-with-copd\#432-advance-care-planning.

4. Hansen E. Successful qualitative health research: a practical introduction. NSW, Australia: Allen and Unwin; 2006.

5. Schoen C, Osborn R, Squires D, Doty M, Pierson R, Applebaum S. New 2011 survey of patients with complex care needs in eleven countries finds that care is often poorly coordinated. Health Affairs 2011;30:2437-48. http://dx.doi.org/10.1377/ hlthaff.2011.0923

6. Health Issues Centre 2010. On my terms...alone at home with care needs: Improving choices. Health Issues Centre, Lincoln Centre for Ageing and Community Care Research, Council for the Ageing Victoria. Aged Care Branch Victorian Health Department, Melbourne, 2010.

7. While C, Duane F, Beanland C, Koch S. Self management of medicines by older people in the community: a person-centred guide to assessment. Melbourne: Royal District Nursing Service, 2011.

8. Mola E, De Bonis JA, Giancane R. Integrating patient empowerment as an essential characteristic of the discipline of general practice/family medicine. Eur J Gen Pract 2008;14(2):89-94. http://dx.doi.org/10.1080/13814780802423463

9. Bainbridge L, Nasmith L, Orchid C, Wood V. Competencies for interprofessional collaboration. Journal of Physical Therapy Education 2010;24(1):6-11.

10. Dean MM. End-of-life care for COPD patients. Prim Care Respir J 2008;17(1):46-50. http://dx.doi.org/10.3132/pcrj.2008.00007

11. Goeman DP, Hogan CD, Aroni RA, et al. Barriers to delivering asthma care: a qualitative study of general practitioners. Med J Aust 2005;183(9):457-60.

12. http://www.respectingpatientchoices.org.au/index.php (accessed 28th June 2012).

13. Lopez A, Shibuya K, Rao C et al. Chronic obstructive pulmonary disease: current burden and future projections. Eur Resp J 2006;27:397-41. http://dx.doi.org/ 10.1183/09031936.06.00025805

\section{2 and never been KISSed: we need to improve the care of children with asthma}

\section{See linked article by Jonsson et al. on pg 276}

\section{${ }^{*}$ Andrew Bush ${ }^{\mathrm{a}}$, Louise Fleming ${ }^{\mathrm{b}}$}

a Professor of Paediatric Respirology, Imperial College, London, UK; and Consultant Paediatric Chest Physician, Royal Brompton Hospital, London, UK

b Clinical Senior Lecturer, Respiratory Paediatrics, Imperial College, London, UK

*Correspondence: Professor Andrew Bush, Department of Paediatric Respiratory Medicine, Royal Brompton Hospital, Sydney Street, London SW3 6NP, UK.

Tel: +44 (0)207351 8232 Fax: +44 (0)207 3518763

E-mail: a.bush@rbh.nthames.nhs.uk

'KISS' - 'Keep It Simple, Stupid' - is sound advice in virtually every clinical situation. In medical school, we focus on getting the basics right and doing the simple things well before rushing headlong into the expensive and elaborate. Asthma in children is common, is the subject of evidence-based guidelines, ${ }^{1}$ and in most cases just requires the KISS approach: get the diagnosis right; give an appropriate level of treatment; make sure the child and family know what it is all about, especially how to use the medication delivery device; and as far as possible eliminate trigger factors from the environment.

And yet, in this issue of the PCRJ, Jonsson et al. demonstrate not merely that the easy is not being done, but indeed, given the opportunity to seize the wrong end of the stick, primary care is doing this with assiduous attention! ${ }^{2}$ So not merely do they report a litany of sins of omission, but all practices had a nebuliser to treat asthma attacks - even though all the evidence is that metered-dose inhalers used with a spacer are at least as safe and effective as the nebulised route in all but the most severe attacks ${ }^{3}$ - and then only if the practice had oxygen available... However, two things must be stated immediately. Firstly, the authors are to be congratulated on performing this study and having the chutzpah to publish the results. Secondly, how many asthma clinics (primary, secondary or even tertiary) inside or outside Sweden would be confident in their performance if submitted to the same scrutiny? Certainly, our experience with really severe asthma is that in at least half of cases there is a need to get the basics right rather than infusing the latest toxic biological. 4,5

This having been said, the results are depressing. The authors studied a large number of children and showed that only a minority had received competent care. ${ }^{2}$ Most would acknowledge that 